\title{
A Study of the Influence of Posterior Column Sensory Sparing on Initial Presentation of Cervical Injuries on the Ultimate Prognosis
}

\author{
G. M. Bedbrook, St. O.B.E., O.St.J., Ms(Melb), HonM.D.(W.A.), \\ HonF.R.C.S.(Ed), F.R.C.S., F.R.A.C.S., D.P.R.M.(Syd) \\ H. G. Prince F.R.C.S. \\ Department of Fracture and Orthopaedic Surgery, University Hospital, Queen's \\ Medical Centre, Nottingham NG7 2UH, U.K.
}

\section{Summary}

From previous papers from five separate Spinal Injury Centres, namely Perth, Western Australia, Stoke Mandeville, U.K., Heidelberg, Germany, Tokushima, fapan and South West Region, U.S.A., a total of 665 patients with cervical spine injuries have been extracted.

These were grouped according to the Frankel classification on neurological status on admission and again on discharge. This has been used to assess the prognosis on the initial classification of the ultimate neurological recovery, as is indicated by the tabulated results.

$A$ small group of Perth patients have been further reviewed, the Frankel $B$ group were sub-divided into $B_{1}$, posterior column sparing only, and $B_{2}$, fuller sensory sparing, to assess any difference in ultimate outcome.

With only small numbers available at present, no major prognostic significance has been demonstrated by using such a division.

Key words: Cervical spine injury; Posterior column sensory sparing; Neurological recovery; Neurological classification.

\section{Introduction}

This paper is mainly a re-appraisal of the patients with cervical injury and neurological deficit seen in the Spinal Unit at Perth from its opening in 1954 to 1982.

The idea for this study was initiated by a discussion between the senior author and his colleagues serving the Perth Spinal Unit as to the value in prognosis of sparing of posterior column, sensation only, after cervical injuries. Did such sensory sparing indicate as good a prognosis for ultimate recovery as does that of preservation of more normal sensation? Posterior column sensation consists of proprioception and touch only, whereas some cases also show some 
pain, temperature and fine touch preservation, implying that the spinothalmic tracts were functioning. A 2 year follow-up allowed re-appraisal of a small but hitherto unused fact.

\section{Method}

Several papers published over the last two decades documented the degree of neurological damage in patients with cervical injuries on admission to spinal units and also their final neurological status. The largest series have come from Stoke Mandeville, Heidelberg, S.W. Arizona and Perth (Frankel et al., 1973, Paeslak et al., 1973, Young and Dexter 1978, Bedbrook and Sakae 1982).

In these centres the basic management of cervical injuries is comparable with initial evaluation of the patient's recovery, motor and physical status. This is followed by the application of support for the neck, with traction, including reduction of the displaced fractures. Postural reduction is usually adequate and certainly always attempted.

The fractures are re-assessed at approximately 6 weeks, then placed in some sort of brace. If they are still unstable at 6 weeks to 3 months post-injury, then surgical stabilisation is carried out in most cases. The individual centres varied in the exact amount of time spent in each stage, with the Arizona series having the highest operative intervention rate in the first three months $(39 \%)$. In Perth the incidence was $10 \%$ in these 3 months.

The groups are also comparable in the aetiology of the fractures. (The Japanese figures quoted in the paper from Perth had a higher incidence of falls from heights.)

The patients in all centres had been classified using the Frankel classification (Frankel 1969) which is as follows:

1. Complete $A$ : The neurological lesion was complete, both motor and sensory, below the segmental level involved.

2. Sensory Sparing only B: Implies useful sensation below the level of the neurological lesion but motor paralysis is complete.

3. Motor Useless $C$ : Some motor function is present below the lesion, but this is of no useful advantage to the patient.

4. Motor Useful D: Implies the presence of useful motor and sensory power below the lesion.

5. Recovery $E$ : Implies that the patient is free of neurological symptoms, i.e. no sensory loss, no weakness, no sphincter disturbance. They may have been some abnormalities of reflexes.

Table I The total number of patients in each of the five centres

\begin{tabular}{lr}
\hline Royal Perth Hospital & 144 \\
Stoke Mandeville & 228 \\
South West Region & 93 \\
Tokushima & 109 \\
Heidelberg & 91 \\
\hline \multicolumn{1}{c}{ Total } & 665 \\
\hline
\end{tabular}


Figure 1 Comparison of Neurological Improvement of each grade. R.P.(R).H. $\mathrm{n}=144$

\begin{tabular}{|c|c|c|c|c|c|}
\hline \multirow{5}{*}{ 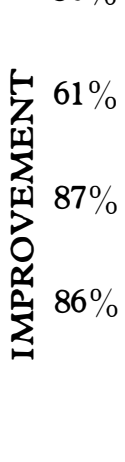 } & $\begin{array}{c}\mathrm{AA} \\
25\end{array}$ & $\begin{array}{c}\mathrm{AB} \\
10\end{array}$ & $\begin{array}{c}\mathrm{AC} \\
3\end{array}$ & $\begin{array}{c}\mathrm{AD} \\
1\end{array}$ & $\mathrm{AE}$ \\
\hline & BA & $\begin{array}{c}\text { BB } \\
7\end{array}$ & $\begin{array}{r}\mathrm{BC} \\
4\end{array}$ & $\begin{array}{c}\mathrm{BD} \\
7\end{array}$ & $\mathrm{BE}$ \\
\hline & $\mathrm{CA}$ & $\begin{array}{c}\mathrm{CB} \\
1\end{array}$ & $\begin{array}{c}\mathrm{CC} \\
2\end{array}$ & $\begin{array}{c}\text { CD } \\
15\end{array}$ & $\begin{array}{c}\mathrm{CE} \\
5\end{array}$ \\
\hline & $\mathrm{DA}$ & $\begin{array}{c}\mathrm{DB} \\
1\end{array}$ & $\mathrm{DC}$ & $\begin{array}{c}\mathrm{DD} \\
7\end{array}$ & $\begin{array}{c}\mathrm{DE} \\
48\end{array}$ \\
\hline & EA & EB & EC & ED & $\begin{array}{c}\mathrm{EE} \\
8\end{array}$ \\
\hline
\end{tabular}

Figure 3 Comparison of Neurological Improvement of each grade. South West Region $n=93$

\begin{tabular}{|c|c|c|c|c|c|}
\hline \multirow{5}{*}{ 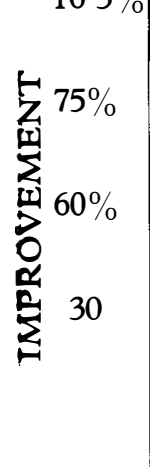 } & $\begin{array}{c}\mathrm{AA} \\
41\end{array}$ & $\begin{array}{c}\mathrm{AB} \\
6\end{array}$ & $\begin{array}{c}\mathrm{AC} \\
1\end{array}$ & $\begin{array}{c}\mathrm{AD} \\
1\end{array}$ & $\mathrm{AE}$ \\
\hline & $\mathrm{BA}$ & $\begin{array}{c}\mathrm{BB} \\
4\end{array}$ & $\begin{array}{c}\mathrm{BC} \\
2\end{array}$ & $\begin{array}{c}\mathrm{BD} \\
10\end{array}$ & $\mathrm{BE}$ \\
\hline & $\mathrm{CA}$ & CB & $\begin{array}{c}\mathrm{CC} \\
2\end{array}$ & $\begin{array}{c}\mathrm{CD} \\
3\end{array}$ & CE \\
\hline & DA & $\mathrm{DB}$ & $\mathrm{DC}$ & $\begin{array}{c}\mathrm{DD} \\
14\end{array}$ & $\underset{6}{\mathrm{DE}}$ \\
\hline & EA & EB & $\mathrm{EC}$ & $\begin{array}{c}\mathrm{ED} \\
3\end{array}$ & $\mathrm{EE}$ \\
\hline
\end{tabular}

Figure 5 Comparison of Neurological Improvement of each grade. Heidelberg

\begin{tabular}{|c|c|c|c|c|c|}
\hline \multirow{5}{*}{ 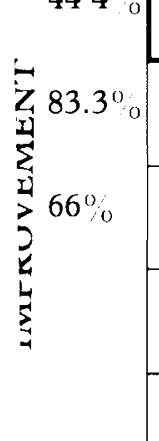 } & $\begin{array}{c}\mathrm{AA} \\
36\end{array}$ & $\begin{array}{c}\mathrm{AB} \\
14\end{array}$ & $\begin{array}{c}\mathrm{AC} \\
0\end{array}$ & $\begin{array}{r}\mathrm{AD} \\
2\end{array}$ & $\begin{array}{c}\mathrm{AE} \\
0\end{array}$ \\
\hline & $\mathrm{BA}$ & $\begin{array}{c}\text { BB } \\
12\end{array}$ & $\begin{array}{c}\mathrm{BC} \\
1\end{array}$ & $\begin{array}{c}\mathrm{BD} \\
9\end{array}$ & $\mathrm{BE}$ \\
\hline & $\mathrm{CA}$ & CB & $\begin{array}{c}\mathrm{CC} \\
2\end{array}$ & $\begin{array}{c}\text { CD } \\
6\end{array}$ & CE \\
\hline & $\mathrm{DA}$ & DB & $\mathrm{DC}$ & $\begin{array}{c}\mathrm{DD} \\
9\end{array}$ & $\mathrm{DE}$ \\
\hline & EA & EB & EC & ED & $\mathrm{EE}$ \\
\hline
\end{tabular}

Figure 2 Comparison of Neurological Improvement of each grade. Stoke Mandeville $\mathrm{n}=218$

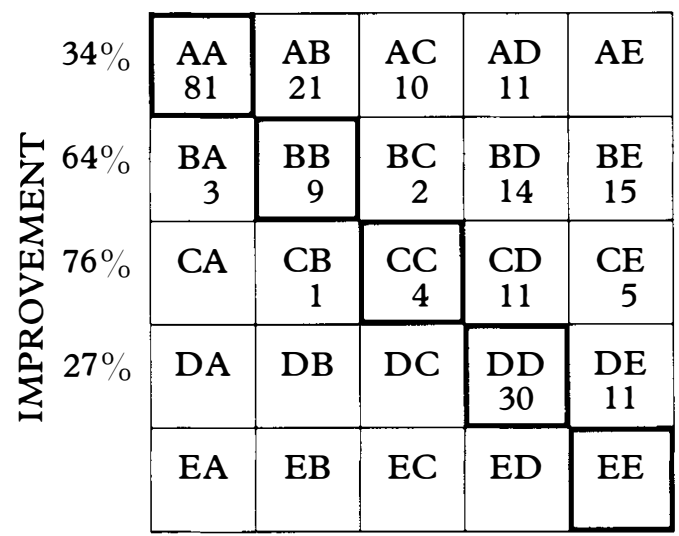

Figure 4 Comparison of Neurological Improvement of each grade. Tokushima (Japan) $n=109$

\begin{tabular}{|c|c|c|c|c|c|}
\hline \multirow[b]{2}{*}{$73 \%$} & $\begin{array}{c}\text { AA } \\
36\end{array}$ & $\begin{array}{c}\mathrm{AB} \\
1\end{array}$ & $\underset{5}{\mathrm{AC}}$ & $\begin{array}{c}\mathrm{AD} \\
23\end{array}$ & $\begin{array}{c}\mathrm{AE} \\
2\end{array}$ \\
\hline & BA & $\begin{array}{c}\text { BB } \\
3\end{array}$ & BC & $\begin{array}{r}\mathrm{BD} \\
4\end{array}$ & $\begin{array}{c}\mathrm{BE} \\
4\end{array}$ \\
\hline $100 \%$ & CA & CB & $\mathrm{CC}$ & $\begin{array}{c}\text { CD } \\
5\end{array}$ & $\begin{array}{c}\mathrm{CE} \\
2\end{array}$ \\
\hline $67 \%$ & $\mathrm{DA}$ & DB & $\mathrm{DC}$ & $\begin{array}{c}\text { DD } \\
8\end{array}$ & $\begin{array}{c}\mathrm{DE} \\
16\end{array}$ \\
\hline & EA & EB & EC & ED & $\mathrm{EE}$ \\
\hline
\end{tabular}

Figure 6 Comparative Prognosis of Neurological grading into $B_{1}$ and $B_{2}$ for ultimate Neurological Status.

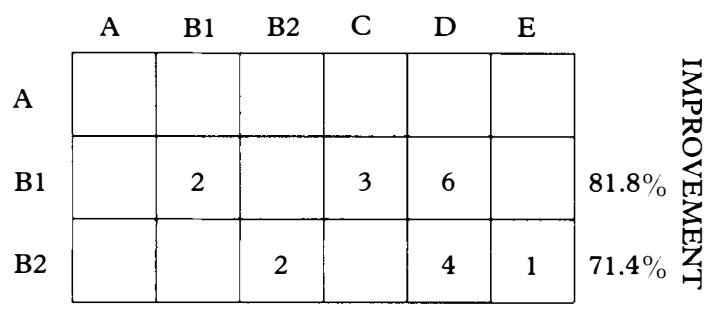


Table II The total number of cases in each group on initial presentation

\begin{tabular}{lr}
\hline Group A & 330 \\
Goup B & 110 \\
Group C & 64 \\
Group D & 150 \\
Group E & 11 \\
\hline
\end{tabular}

The results from the five centres are shown in Figures 1 to 5 .

Taking all five groups together as from the published work quoted, the overall improvement rate is:

$\begin{array}{ll}\text { Group A } & 33 \cdot 3^{\circ}{ }^{\circ} \\ \text { Group B } & 71 \cdot 3^{\circ}{ }^{\circ} \\ \text { Group C } & 85 \cdot 0^{\circ}{ }^{\circ} \\ \text { Group D } & 54 \cdot 5^{\circ}{ }^{\circ}\end{array}$

The low figures for improvement in Group D, who presumably have initially less trauma, are due to problems with this method of classification. There is a wide gap clinically between Group D and Group E. Yeo (1984) advocates further sub-groups.

It was decided to make a more detailed study of the patients from Perth in Group B as it was felt the sparing of posterior column sensation only did not give such a good prognosis for recovery as did the maintenance of other sensory modalities. A further sub-division of Frankel's Group into $B_{1}$ and $B_{2}$ was attempted.

$\mathrm{B}_{1}=$ Posterior column sparing only.

$\mathrm{B}_{2}=$ Sensory sparing for discriminative fine touch as well as posterior column.

\section{Results}

The 18 patients in Group B from the 1982 paper had their initial notes reassessed and 4 further cases in Group B admitted during 1982 were also assessed. Eighteen cases had been adequately documented on their initial sensory charting to divide into Group $\mathrm{B}_{1}$ or $\mathrm{B}_{2}$ (Fig. 6).

11 Cases were classified as $\mathrm{B}_{1}$

7 Cases were classified as $\mathrm{B}_{2}$

$81.8^{\circ}$ of $\mathrm{B}_{1}$ improved

$71.4^{\circ}{ }_{0}$ of $\mathrm{B}_{2}$ improved

\section{Conclusions}

Although the figures are too small to be statistically significant, it would appear that the sparing of posterior column sensation only gives as good a prognosis as in patients with fuller sensory sparing, although initially it suggests more severe cord damage. It would be interesting to look more closely at the patients from 
the other four centres to break down the classification into $B_{1}$ and $B_{2}$ to see if this initial result stands in a more statistically valuable number of patients.

The results from Perth as they stand suggest that the Frankel Grade B classification does not need further sub-division. The unexpected and wide discrepancy in the prognosis of Grade $\mathrm{C}$ and $\mathrm{D}$ patients, $86 \%$ and $32 \%$ respectively, shows a state that may manifest a weakness of the classification in those better grades, in that the neurological divisions are not precise enough.

\section{References}

BEDBROOK GM, SAKAE MD 1982 A review of cervical injuries with neurological dysfunction. Paraplegia 20:321-333.

FRANKEL HL et al. 1969 The value of postural reduction in the initial management of closed injuries of the spine with paraplegia and tetraplegia. Paraplegia 7:179-192.

FRANKEL HL et al. 1973 Results of conservative treatment of vertical compression injuries of the cervical spine. Proceedings of 19th Veterans' Administration Spinal Cord Injury Conference, Scottsdale, Arizona, 28-32.

FRANKEL HL et al. 1973 Results of conservative treatment of extension injuries of the cervical spine with tetraplegia. Proceedings of 19th Veterans' Administration Spinal Cord Injury Conference, Scottsdale, Arizona, 52-56.

PAESLAK V et al. 1973 Results of conservative treatment of flexion fractures and flexion rotation fracture disolocation of the cervical spine with tetraplegia. Proceedings of 19th Veterans' Administration Spinal Cord Injury Conference, Scottsdale, Arizona, 39-42.

YEO JD 1984 Personal communication with Senior Author.

Young JS, DexTER WR 1978 Neurological recovery distal to the zone of injury in 172 cases of closed traumatic spinal cord injury. Paraplegia 16:39-49. 